\title{
Detection of the Moderately Beneficial Cognitive Effects of Low-Dose Treatment with Haloperidol or Clozapine in an Animal Model of the Attentional Impairments of Schizophrenia
}

\author{
Vicente Martinez' and Martin Sarter", \\ 'Department of Psychology, University of Michigan, Ann Arbor, MI, USA
}

\begin{abstract}
The absence of effective cognition enhancers for the treatment of patients with schizophrenia limits the validation of animal models and behavioral tests used for drug finding and characterization. However, low doses of haloperidol and clozapine were documented to produce moderately beneficial effects in patients. Therefore, this experiment was designed to determine the attentional effects of such treatments in a repeated-amphetamine (AMPH) animal model. Animals were trained in an operant-sustained attention task and underwent a 40-day pretreatment period with saline or increasing doses (1-10 mg per $\mathrm{kg}$ ) of AMPH. After regaining baseline performance following 10 days of saline treatment, animals were treated with haloperidol $(0.025 \mathrm{mg}$ per kg), clozapine (2.5 mg per kg), or vehicle for 10 days. Furthermore, the effects of AMPH challenges ( $1.0 \mathrm{mg}$ per kg) were assessed. In AMPH-pretreated animals, the administration of $\mathrm{AMPH}$ challenges resulted in the disruption of attentional performance. Treatment with haloperidol and clozapine attenuated the detrimental performance effects of these challenges, with clozapine exhibiting more robust attenuation. Furthermore, clozapine, but not haloperidol, impaired the performance of control animals. In contrast, the performance of AMPH-pretreated animals remained unaffected by clozapine. As this animal model detects the moderately beneficial cognitive effects of haloperidol and clozapine, it may be useful for preclinical research designed to detect and characterize treatments for the cognitive symptoms of schizophrenia. Neuropsychopharmacology (2008) 33, 2635-2647; doi:I0.1038/sj.npp. I30 I66I; published online I9 December 2007
\end{abstract}

Keywords: schizophrenia; attention; amphetamine; haloperidol; clozapine; animal model

\section{INTRODUCTION}

The preclinical detection and characterization of treatments for the cognitive symptoms of schizophrenia has remained a major challenge, in part because of the paucity of animal models of the disease and of widely accepted standards for validation of such models (Sarter, 2006; Sarter et al, 1992a,b). The absence of clinically effective cognition enhancers has often been cited as a major hindrance for current validation efforts. However, as was stressed by Hagan and Jones (2005), preclinical studies have rarely detected the small pro-cognitive effects of antipsychotic drugs observed in patients. In the absence of true benchmark drugs, the demonstration of such effects in animal models would greatly assist in closing the 'translational gap' that characterizes the preclinical research in this field (Floresco et al, 2005).

Although intensely discussed in the literature, the widely held views that first- and second-generation antipsychotics (F/SGAs) are devoid of pro-cognitive effects (Hajos, 2006),

\footnotetext{
*Correspondence: Dr M Sarter, Department of Psychology, University of Michigan, 530 Church Street, 4032 East Hall, Ann Arbor, Ml 48I09-I043, USA, Tel: + I 743764 6392, Fax: + I 734763 7490,

E-mail: msarter@umich.edu

Received 27 September 2007; revised 16 November 2007; accepted 19 November 2007
}

or that SGAs are more efficacious in improving the cognitive status of schizophrenic patients, are not completely consistent with the clinical evidence. Rather, several studies indicated that members of both classes of antipsychotic drugs produce moderate and largely equivalent improvements in cognitive function, particularly when administered at relatively low doses (Green et al, 2002; Harvey et al, 2005; Keefe et al, 2006b; Mishara and Goldberg, 2004; Remillard et al, 2005; Rollnik et al, 2002). Thus, the goal of our research was to define an animal model capable of detecting the limited beneficial cognitive effects of low-dose treatment of an FGA (haloperidol) and an SGA (clozapine; see 'Methods' for the definition and justification of low doses of either drug; Kapur et al, 2003).

Because attentional impairments have been widely considered to represent a central target for treatment (Braff and Light, 2004; Hajos, 2006; Robbins, 2005), an operant procedure for the test of attention in rats was employed in this research. This task was previously demonstrated to generate measures reflecting sustained attention performance (McGaughy and Sarter, 1995). As described below, this task requires the animals to report the presence or absence of visual signals on the basis of distinct signal and nonsignal trials, with rewards delivered for both hits (detection of signals) and correct rejections (correct responses in nonsignal trials). The performance of this task requires the integrity of the cortical cholinergic input 
system and evokes significant increases in cortical acetylcholine (ACh) release (Arnold et al, 2002; Kozak et al, 2006; McGaughy et al, 1996; McGaughy and Sarter, 1998). Recent evidence indicated that the shifting between trials requiring the reporting of the absence of a signal and trials involving signal detection represents a key behavioral and cognitive component of this task that is mediated via transient prefrontal cholinergic activity (Parikh et al, 2007).

Repeated administration of psychostimulants has been shown to model important neurobiological, behavioral, and cognitive aspects of schizophrenia, including a sensitized mesolimbic dopamine system and impairments in attentional performance (Castner and Goldman-Rakic, 1999, 2003; Castner et al, 2004, 2005; Crider et al, 1982; Dalley et al, 2005; Featherstone et al, 2007; Fletcher et al, 2005, 2007; Kapur, 2003; Martinez et al, 2005; Robinson and Becker, 1986; Russig et al, 2002; Tenn et al, 2003, 2005). Based on extensive evidence indicating the crucial role of the cortical cholinergic input system for attention (Kozak et al, 2006; Parikh et al, 2007; Sarter et al, 2006, 2005a), the attentional symptoms of schizophrenia have been proposed to be mediated via abnormalities in the regulation and activity of this neuronal system (Martinez et al, 2005; Raedler et al, 2003, 2007; Sarter et al, 2005b). Recently, we demonstrated that in animals pretreated in accordance with an amphetamine (AMPH) regimen identical to the one used herein, the disruption of attentional performance triggered by AMPH challenges was a result, not just a correlate, of a prefrontal cholinergic input system that remained 'frozen' at baseline and failed to activate in response to the task onset (Kozak et al, 2007). The tests of AMPH challenges in these experiments have been thought to model active disease periods and relapse, associated with acute dopaminergic dysregulation (Laruelle, 2000; Laruelle and Abi-Dargham, 1999; Laruelle et al, 1999; Lieberman et al, 1997; Moghaddam, 2002; Yui et al, 1999).

Our previous studies utilized an AMPH pretreatment regimen characterized by increasing doses over a 40-day period (Paulson et al, 1991; Robinson and Camp, 1987; Robinson et al, 1988). This regimen was demonstrated to produce lasting sensitization of the mesolimbic dopamine system and locomotor activity without yielding neurotoxicity. Importantly, psychomotor sensitization, locomotor hyperactivity, or stereotypes are not observed in attentional task-performing rats following AMPH challenges in AMPHpretreated animals, perhaps as a result of the constraining of the animals' behavior by the operant and attentional requirements of the task (Kozak et al, 2007; Martinez et al, 2005). This regimen was employed in the present experiment to test the hypothesis that subchronic administration of low doses of clozapine and haloperidol attenuate the attentional impairments observed following AMPH challenges in AMPH-pretreated animals.

\section{METHODS}

\section{Subjects}

Forty-two male Sprague-Dawley rats (Harlan, Indianapolis, IN; aged 3 months and weighing $422 \pm 17 \mathrm{~g}$ (mean \pm SEM) at the beginning of the experiment) were housed in singlestandard cages with corncob bedding in a humidity- $(\sim 45 \%)$ and temperature $\left(23^{\circ} \mathrm{C}\right)$-controlled environment. Animal care, facilities, and experimental procedures were in accordance with protocols approved by the University Committee on Use and Care of Animals at the University of Michigan. Lighting followed a 12-h light-dark cycle (lights on at 0600). Testing took place between 0800 and 0530 hours. Recent evidence indicated that animals trained and tested daily in a cognitively demanding task shift their circadian rhythm to a diurnal pattern (Sutton B, Martinez V, Sarter $\mathrm{M}$ and Lee $\mathrm{T}$, unpublished observation), suggesting the suitability of animal testing during day time hours. Animals were handled extensively prior to the initiation of behavioral training. Rats were water deprived to approximately $95 \%$ of free-access weight. Access to water was limited to a 30-min period in the home cage following daily behavioral testing. Approximately $5 \mathrm{ml}$ of water was earned additionally as reward during each daily session of operant testing. Food (Rodent Chow, Harlan Teklad, Madison, WI) was provided ad libitum in the home cage.

\section{Apparatus}

Behavioral training and testing took place in 12 operant chambers (Med-Associates, St Albans, VT). Each operant chamber was enclosed within a sound-attenuating compartment and equipped with two retractable levers, one house light $(2.8 \mathrm{~W})$, a central panel light, and a water dispenser located in between the levers. Ventilation and white noise were provided by a fan mounted on the wall of the soundattenuating compartment. Signal presentation, lever operation, water delivery, and data collection were controlled by a PC running Med-PC for Windows software (V4.1.3; MedAssociates).

\section{Behavioral Training}

Evidence indicating the validity of the operant procedure described below, in terms of generating measures of sustained attention performance, was described earlier (Martinez and Sarter, 2004; McGaughy et al, 2000, 1996; McGaughy and Sarter, 1995, 1998). Operant training took place 7 days/week. Rats were placed in unlit chambers for $20 \mathrm{~min}$ prior to the task onset to acclimate. Animals were first trained to press a lever for a water reward $(30 \mu \mathrm{l}$ per reward) in accordance with a modified fixed-ratio 1 schedule of reinforcement. During phase two of shaping, animals were trained to respond to the presentation of signals and discriminate between signal events (illumination of the central panel light for $1 \mathrm{~s}$ ) and nonsignal events (nonillumination of light). The sequence of signal or nonsignal events was randomized. After $2 \mathrm{~s}$ of the occurrence of a signal or nonsignal event, both levers were extended into the chamber and remained active for $4 \mathrm{~s}$ or until a response occurred. If the animal failed to respond within $4 \mathrm{~s}$ the levers were retracted and an omission was scored. Immediately following a response (either correct or incorrect), both levers were retracted and a variable intertrial interval (ITI; $12 \pm 3 \mathrm{~s}$ ) was reset. During signal trials, depression of the left lever indicated a correct response and was scored as a hit, whereas depression of the right lever indicated an incorrect response and was scored as a miss. Conversely, during nonsignal trials 
depression of the left lever indicated an incorrect response and was scored as a false alarm and depression of the right lever indicated a correct response and was scored as a correct rejection. Animals received water reward only for correct responses (hits and correct rejections), incorrect responses (misses and false alarms) triggered the ITI and had no further scheduled effects. During this phase of training, incorrect responses resulted in the trial being repeated up to three times in the form of correction trials. If the animals continued to respond incorrectly following three correction trials, a forced-choice trial was initiated. A forced-choice trial consisted of a signal or nonsignal event followed by extension of only the correct lever into the operant chamber for $90 \mathrm{~s}$ or until a lever press occurs. In the event that the forced-choice trial was a signal trial, the signal light remained illuminated for as long as the lever was extended. Correction trials served to counter the manifestation of side- and/or lever biases. The house light remained off during this shaping phase. Behavioral sessions consisted of 162 trials per session. Following 3 consecutive days of responding correctly to $\geqslant 59 \%$ of both signal- and nonsignal trial animals progressed to the next stage of training.

During the third phase of shaping, signal durations were shortened to 500,50 , or $25 \mathrm{~ms}$ ( 27 trials per duration) and the ITI was reduced to $9 \pm 3 \mathrm{~s}$. Correction and forced-choice trials were eliminated. Sessions were designed so that they consisted of three blocks of 54 trials each, with all signal durations occurring randomly nine times per block. Animals were advanced to the final stage of shaping when their performance met or exceeded a performance criterion of $70 \%$ of correct responses to the $500 \mathrm{~ms}$ signal trials, $70 \%$ correct responses to nonsignal trials, and fewer than 20 omitted trials per session. During the final stage of shaping, the house light was illuminated throughout the entire testing session. The illumination of the house light represents a crucial step as it requires animals to constrain their exploratory and grooming behavior and maintain orientation toward the central panel light during task performance. Upon reaching the final criterion of $\geqslant 70 \%$ correct responses to the $500 \mathrm{~ms}$ signal trials, $\geqslant 70 \%$ correct responses to nonsignal trials and fewer than that 20 omissions per sessions for a minimum of three consecutive sessions, the drug pretreatment regimen was initiated. The average time to complete the entire shaping period was approximately 3 months for all animals.

\section{Measures of Performance}

Performance measures generated by this procedure include the relative number of hits, misses, false alarms, and correct rejections. To obtain an overall measure of performance that reflects the animals' accuracy in both signal and nonsignal trials, a 'vigilance index' was calculated $\left.\left(\mathrm{VI}=9(\mathrm{~h}-\mathrm{f}) / 2 \times(\mathrm{h}+\mathrm{f})-(\mathrm{h}+\mathrm{f})^{2}\right)\right)$. VI is a modification of the sensitivity index (Frey and Colliver, 1973) and is based on the relative number of correct responses as opposed to the probability for such responses, thereby removing errors of omissions from this index. VI values range from -1 to 1 , with a score of 1 indicating that all responses were hits and correct rejections, 0 indicating random lever selection, and -1 reflecting that all responses were misses and false alarms. In addition, errors of omission and latencies between signal or nonsignal events and bar presses were recorded. Parametric statistical analyses of percentage data were conducted using arcsine-transformed values (Zar, 1974).

\section{AMPH Pretreatment Regimen}

Animals were divided into two groups designated to receive pretreatment with either AMPH (1-10 mg per kg; salt weight, dissolved in $0.9 \%$ saline; $n=21$; Figure 1 ) or saline $(1.0 \mathrm{ml} / \mathrm{kg} ; n=21$; see 'Introduction' for background on the escalating dosing regimen of AMPH). Rats were matched for performance before being assigned to the two pretreatment conditions to ensure equivalent performance levels for the two groups. Intraperitoneal (i.p.) injections were administered twice daily, at 0900 inside the testing room ( 20 min prior to the task onset) and again $8 \mathrm{~h}$ later in the home cage environment. AMPH pretreatment spanned 40 days (Figure 1). AMPH was administered 5 days/week, with saline $(0.9 \%, 1.0 \mathrm{ml} / \mathrm{kg})$ administered on the weekends. The intermittency and escalation of this dosing regimen purposefully mimics the 'runs and crashes' pattern of AMPH abuse typically exhibited by addicts and that is a

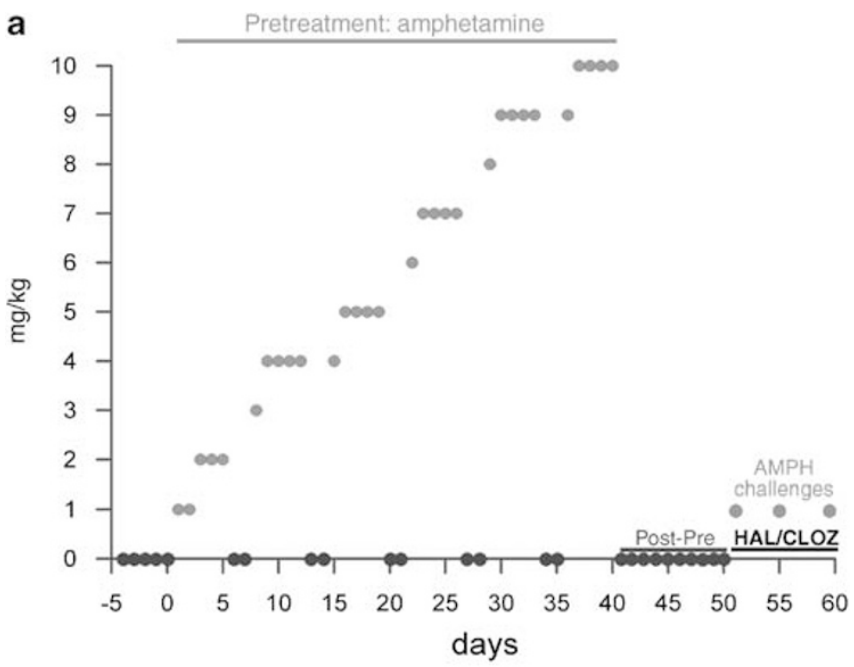

b

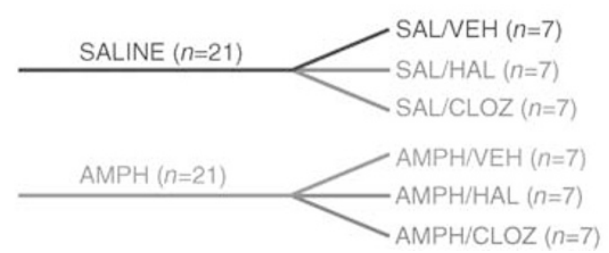

Figure I Pretreatment regimen, experimental design and experimental groups. (a) Illustration of the pretreatment regimen consisting either of the administration of increasing doses of amphetamine (AMPH) or of saline (SAL). Note that after every fifth dose of $A M P H$, two drug-free (SAL) sessions/days were inserted (see 'Introduction' for justification). All animals received SAL during a I0-day post-pretreatment (post-pre) period. Thereafter, groups were split to receive haloperidol ( $0.025 \mathrm{mg}$ per $\mathrm{kg}$ ), clozapine (2.5 mg per kg), or acidic vehicle for 10 days. On days I, 5, and 10 of this regimen, the effects of AMPH challenges, at a dose that does not affect the performance of naive animals ( $1.0 \mathrm{mg}$ per $\mathrm{kg}$ ), were assessed in all six experimental groups. (b) Summary of experimental groups and the number of animals per treatment condition. 
critical characteristic of treatment regimens that trigger psychosis (Angrist, 1994; Paulson et al, 1991; Robinson and Camp, 1987; Robinson et al, 1988). Moreover, as performance is disrupted as a result of high omissions following doses $>2 \mathrm{mg}$ per $\mathrm{kg}$, partial performance recovery during drug-free weekends serves to indicate that the memory for the task rules remains unaffected by this treatment regimen and enhances the recovery of the animals' performance immediately after completion of the regimen (Kozak et al, 2007; Martinez et al, 2005). As the administration of AMPH doses of $>2 \mathrm{mg}$ per $\mathrm{kg}$ resulted in $>90 \%$ errors of omissions, these rats practiced the task only twice weekly, during the drug-free weekends. In order to control for potentially confounding effects of limited practice, animals pretreated with saline were permitted to perform the task only twice weekly. During other days, these animals were transported into the test chambers but the task was not activated. Following the completion of the pretreatment with AMPH or saline, all animals received saline injections for 10 days. This 10-day period was followed by the administration of haloperidol or clozapine and the test of AMPH 'challenges' at time points previously demonstrated to reveal disruption of attentional performance in AMPHpretreated animals (Martinez et al, 2005).

\section{Treatment with Clozapine or Haloperidol}

Following the 10-day of saline treatment, groups were further subdivided into cohorts designated to receive subchronic treatment with haloperidol (HAL: $0.025 \mathrm{mg}$ per $\mathrm{kg}$; s.c.), clozapine (CLOZ: $2.5 \mathrm{mg}$ per $\mathrm{kg}$; s.c.), or acidic vehicle $(1.0 \mathrm{ml} / \mathrm{kg}$; see Figure $1 \mathrm{~b}$ for an illustration of treatment groups).

Justification of doses and treatment regimen. As discussed in the 'Introduction', this experiment intended to test the putative cognitive efficacy of relatively low doses of clozapine and haloperidol. In clinical studies assessing effects of low doses of haloperidol, approximately $5 \mathrm{mg}$ per day have been administered (Green et al, 2002; Keefe et al, 2006b). Based on measures of D2 receptor occupancy, Kapur et al (2003) concluded that in order to achieve D2 receptor occupancy in the rat that corresponds with D2 occupancy in patients following clinically effective doses (65-80\% D2 occupancy), 0.04-0.08 mg per kg haloperidol needs to be administered. Defining a low dose in terms of lower, 50\% D2 receptor occupancy, $0.025 \mathrm{mg}$ per $\mathrm{kg}$ (Li et al, 2007a) was selected as a dose (see also Table 1 in Kapur et al, 2003). Haloperidol was administered for 10 days and given $30 \mathrm{~min}$ prior to the task onset, so that performance was assessed while plasma levels rose and before reaching the half-life point for haloperidol in rats (Cheng and Paalzow, 1992). The selection of a low dose of clozapine $(2.5 \mathrm{mg}$ per $\mathrm{kg}$ ) likewise followed the rationale suggested by Kapur et al (2003; see their Table 1). Clozapine was given $40 \mathrm{~min}$ prior to the task onset and, similar to haloperidol, for 10 days. On the days of AMPH challenges, clozapine or the vehicle for clozapine was administered $20 \mathrm{~min}$ prior to $\mathrm{AMPH}$, or $40 \mathrm{~min}$ prior to task onset. Haloperidol or the vehicle for haloperidol was administered $10 \mathrm{~min}$ prior to $\mathrm{AMPH}$, or $30 \mathrm{~min}$ prior to the task onset. This dose of clozapine is significantly smaller than acute doses shown to attenuate the behavioral effects of phencylcidine (Abdul-Monim et al, 2006; Dunn and Killcross, 2006) and was found to have little effects on the performance of rats in the five-choice serial reaction time task when given acutely or chronically (Amitai et al, 2007). Finally, as discussed in Kapur et al (2003), it needs to be noted that the present administration regimen for clozapine and haloperidol does not reproduce plasma levels that match those observed in patients. However, the necessity of achieving such levels in animals for the demonstration of efficacy remains a very complex and unresolved issue.

During the treatment with haloperidol or clozapine, AMPH was co-administered as a 'challenge' ( $1 \mathrm{mg}$ per $\mathrm{kg}$ ) on days 1, 5, and 10 of the antipsychotic drug treatment schedule (days 11, 16, and 21 following cessation of treatment; see Figure 1). These time points were based on the prior observation that the performance of AMPHpretreated animals returned to baseline after $\sim 10$ days following the completion of the pretreatment period (Martinez et al, 2005) and on pilot data indicating that the performance effects of AMPH challenges manifested at the same time.

\section{Statistical Analyses}

Statistical analyses were conducted using mixed designs. Generally the main effects and interactions of the factors pretreatment (AMPH/SAL) and treatment (CLOZ, HAL, or $\mathrm{VEH})$ were examined with respect to the factors signal duration (500, 50, $25 \mathrm{~ms}$, where applicable) and the factor time (below). Baseline performance was based on the averages of the performance data from the final 3 days prior to the start of pretreatment and analyzed using mixed ANOVAs on the factors group (designated for subsequent $\mathrm{AMPH}$ - or saline-pretreatment) and signal duration. Next, the effects of acute administration of AMPH were determined by contrasting task performance of AMPH and SAL animals following the acute administration of $1 \mathrm{mg}$ per $\mathrm{kg}$ AMPH. Performance during the entire course of the 40-day escalating AMPH regimen could not be fully assessed due to high rates of omissions in AMPH-pretreated rats following higher doses of AMPH. To provide an indication of the animals' residual performance during the pretreatment regimen, data from these drug-free periods were analyzed by averaging performance measures over 2 days, to yield five time points (one per period). These data were analyzed using a mixed ANOVA that included the factors group (AMPH vs saline pretreated) and, where applicable, signal duration. Following the completion of the pretreatment regimen, data from the subsequent posttreatment 10 -day period were analyzed by first collapsing data into three blocks consisting of days 1-3 (P1), 4-7 (P2), and 8-10 (P3). Mixed ANOVAs for the factors group, time (P1, P2, and P3) and signal duration were computed. Using a similar analysis, data from P3 were contrasted with baseline data to determine the recovery of performance by the end of this 10-day period. The effects of AMPH challenges were determined by conducting mixed design ANOVAs over the factors group, time (challenge 1, 2, 3), and signal duration. The primary analysis contrasted the effects of AMPH/VEH and SAL/VEH animals. Subsequent analyses were conducted separately on AMPH- and saline-pretreated 
groups undergoing treatment with clozapine or haloperidol. These analyses focused on comparing the performance of $\mathrm{AMPH} / \mathrm{HAL} v s \mathrm{AMPH} / \mathrm{VEH} v s \mathrm{SAL} / \mathrm{VEH}$ rats, and AMPH/ $\mathrm{CLOZ} v s \mathrm{AMPH} / \mathrm{VEH}$ vs SAL/VEH rats, followed by multiple comparisons where applicable. When appropriate, post hoc analyses were carried out using one-way ANOVAs and the least significant difference (LSD) test. Exact $p$-values were reported (Greenwald et al, 1996). Statistical analyses were carried out on SPSS Version 14.0 for Windows (SPSS Inc., Chicago, IL).

\section{RESULTS}

\section{Baseline Performance}

Baseline performance was determined based on data from the last three sessions/days prior to the initiation of the AMPH/SAL pretreatment regimen (see Figure 1 for an illustration of the treatment regimen and experimental groups). The performance of animals assigned to subsequent AMPH vs SAL pretreatment did not differ (VI: $\mathrm{F}(1,40)=2.53 ; p=0.11 ;$ hits: $\mathrm{F}(1,40)=1.475 ; p=0.232$; correct rejections: $\mathrm{F}(1,40)=1.15 ; \quad p=0.289$; omissions $\mathrm{F}(1,40)=2.42 ; p=0.12)$. VI scores and hits depended on signal duration (VI: $\mathrm{F}(2,80)=247.24 ; p<0.001 ; \mathrm{M} \pm \mathrm{SEM}$ : $500 \mathrm{~ms}: 0.64+0.02 ; 50 \mathrm{~ms}: 0.33 \pm 0.03 ; 25 \mathrm{~ms}: 0.14 \pm 0.03$; hits: $\quad \mathrm{F}(2,80)=261.97 ; \quad p<0.001 ; \quad(\mathrm{M} \pm \mathrm{SEM}): 500 \mathrm{~ms}$ : $83.47 \pm 1.93 \%$; $50 \mathrm{~ms}: 52.79 \pm 2.64 \%$; $25 \mathrm{~ms}: 35.35 \pm 2.21 \%$ ). Animals responded correctly to $78.96 \pm 1.23 \%$ of nonsignal trials and omitted $4.00 \pm 6.03 \%$ of trials per session.

\section{Effects of Acute AMPH Administration}

The first dose of AMPH given at the beginning of the AMPH-pretreatment regimen was $1.0 \mathrm{mg}$ per $\mathrm{kg}$. As the effects of this dose were employed later for comparisons with the effects of AMPH challenges, the acute effects of this first dose on performance were analyzed to confirm that it did not affect the performance of animals lacking prior exposure to AMPH (Martinez et al, 2005). As expected, the acute administration of this dose did not affect the animals' performance when compared with saline (VI: $\mathrm{F}(1,40)=0.49$; $p=0.48$; omissions: $\mathrm{F}(1,40)=2.71 ; p=0.10$ ).

\section{Performance during AMPH Pretreatment}

As previously observed, following doses $>2 \mathrm{mg}$ per $\mathrm{kg}$, animals omitted the majority of the trials (Martinez et al, 2005). However, robust performance recovery was observed during the weekly 2 days when saline was given to all animals. Compared to SAL animals, the performance of animals receiving AMPH remained impaired during these drug-free days (VI: $\mathrm{F}(1,40)=8.84 ; p=0.005$ ) but their residual performance did not further decline over the 5 weeks $(\mathrm{F}(4,160)=0.44 ; \quad p=0.77 ; \quad$ group $\times$ week: $\mathrm{F}(4,160)=2.07 ; p=0.09)$. Figure 2 illustrates VI scores, collapsed over all signal durations, for the weekly 2-day drug-free period. The lower overall performance of AMPHtreated animals was largely due to decreases in hits (main effect of group: $\mathrm{F}(1,40)=6.29 ; p=0.02$ ), while the animals' performance in nonsignal trials recovered to the levels of SAL animals during the weekly 2 -day drug-free periods

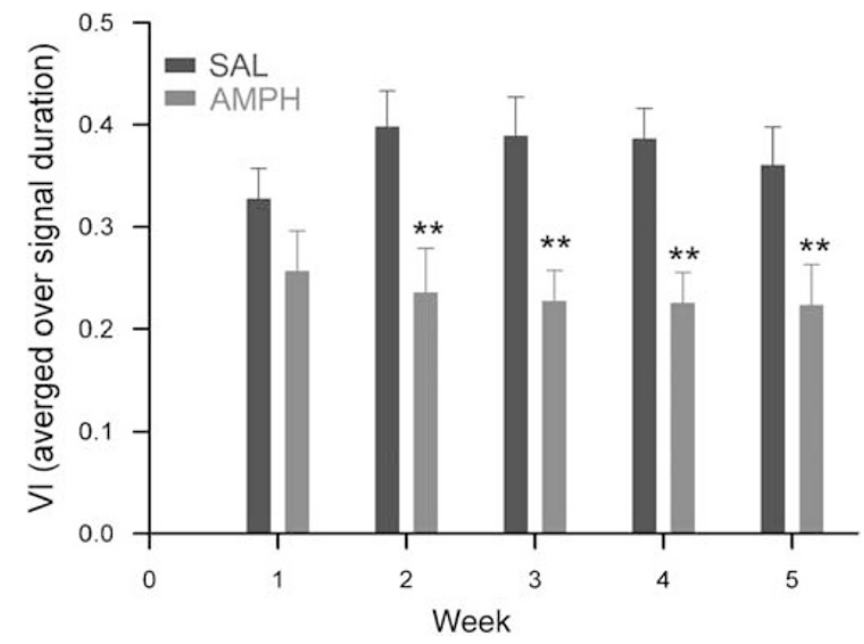

Figure 2 Performance of amphetamine (AMPH)- and saline (SAL)pretreated animals during the 2-day drug-free period that was followed 5 days of AMPH administration. While performance following the administration of AMPH at doses $>2 \mathrm{mg}$ per $\mathrm{kg}$ was characterized by high levels of omissions and cessation of performance, performance recovered significantly during the 2-day drug-free period. The graph depicts overall performance (vigilance index (VI); M, SEM) during the five 2-day drug-free periods. The performance of AMPH animals remained moderately impaired compared with SAL animals after the first week of AMPH pretreatment (chance performance would be indicated by $\mathrm{VI}=0$; *** $p<0.0$ I; multiple comparisons; see 'Results' for statistical findings).

$(\mathrm{F}(1,40)=0.34 ; p=0.56)$. The number of trials omitted during these drug-free periods did not differ between groups $(\mathrm{F}(1,40)=0.516 ; p=0.47)$ and did not change as a function of week $(\mathrm{F}(4,160)=2.33 ; p=0.058$; week $\times$ group: $(\mathrm{F}(4,160)=1.59 ; p=0.18 ; 9.80 \pm 2.00 \%$ omissions per session $(M, S E M))$.

\section{Performance Following AMPH Pretreatment}

In order to determine the immediate effects of completion of the AMPH pretreatment regimen and the potential recovery of performance, data from the 10-day postpretreatment period were divided into three posttreatment blocks $(\mathrm{P} 1=$ days $1-3 ; \mathrm{P} 2=$ days $4-7 ; \mathrm{P} 3=$ days $8-10)$. The analysis of VI indicated that the performance of animals exposed to AMPH remained impaired during the first 3 days and then recovered rapidly (main effect of group: $\mathrm{F}(1,40)=3.01 ; \quad p=0.09 ; \quad$ group $\times$ block: $\mathrm{F}(10,72)=2.06$; $p=0.04)$. Multiple comparisons indicated that group differences were significant for P1 $(\mathrm{F}(1,40)=7.4 ; p=0.01)$ but not P2 and P3 (both $p>0.15$; Figure 3).

The initially lower overall performance in AMPH-treated animals was due to impaired performance in both signal trials and nonsignal trials. The recovery of signal trial performance was reflected by a significant interaction between group and days $(\mathrm{F}(2,80)=03.93 ; p=0.02$; group: $\mathrm{F}(1,40)=0.87 ; p=0.35$ ). Multiple comparisons failed to indicate significant differences between the groups at the three time points (all $p>0.17$ ), but revealed a significant improvement in hits in AMPH-pretreated $(\mathrm{F}(2,40)=8.18$; $p=0.003)$, but not SAL-pretreated animals $(\mathrm{F}(2,40)=0.09$; $p=0.84)$. Furthermore, the performance of AMPHpretreated animals improved from P1 to P2 $(\mathrm{LSD}=0.07$; $p=0.02)$ and P2 to P3 ( $\operatorname{LSD}=0.11 ; p=0.04)$, and these 


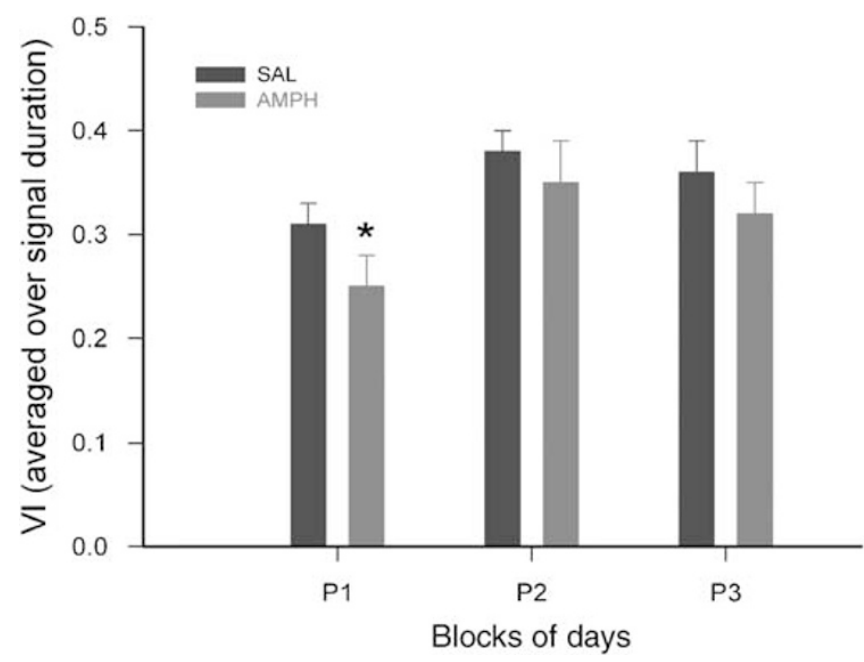

Figure 3 Overall performance (vigilance index (VI); M, SEM), averaged over during the post-pretreatment, I0-day period during which all animals received saline. To determine performance recovery during the period, data were blocked for analysis $(\mathrm{PI}=$ days $\mathrm{I}-3$; P2 = days 4-7; P3 = days 8-10). Performance remained moderately impaired during $\mathrm{PI}$ and recovered subsequently ${ }^{*} p<0.05$ based on multiple comparisons; see 'Results' for analyses of hits and correct rejections). During P3, all animals performed at levels similar to the baseline recorded prior to the amphetamine (AMPH)-pretreatment regimen.

animals' performance at P3 was significantly better than at P1 $(L S D=0.18 ; p=0.003)$. The initial impairments in the performance in nonsignal trials were even more robust as indicated by a main group effect $(\mathrm{F}(1,40)=5.18 ; p=0.03$; group $\times$ day: $\mathrm{F}(2,80)=0.024 ; p=0.87)$ and recovered more slowly as reflected by significant group differences at $\mathrm{P} 1$ and P2 but no longer at P3 $(\mathrm{P} 1: \mathrm{F}(1,40)=7.02 ; p=0.01 ; \mathrm{P} 2$ : $\mathrm{F}(1,40)=4.37 ; p=0.04 ; \mathrm{P} 3: \mathrm{F}(1,40)=3.29 ; p=0.07)$.

Importantly, by the last block of days during this 10-day period (P3), the animals' performance (VI) had returned to the baseline levels observed prior to the initiation of the pretreatment regimen (group: $\mathrm{F}(1,40)=0.02 ; p=0.96$ ). Although this analysis indicated an interaction between group and the two time points (main effect of time: $\mathrm{F}(1,40)=0.37 ; p=0.054)$, time $\times$ group: $\mathrm{F}(2,80)=10.42$; $p=0.02)$, multiple comparisons failed to specify the source for this interaction (all $p>0.11$ ). Inspection of the data indicated that this interaction appeared to reflect a slightly lower level of performance of SAL animals at baseline when compared with P3 (baseline: $0.34 \pm 0.05$; P3: $0.40+0.04$ ) combined with a slightly higher performance of AMPH animals at baseline when compared with P3 (baseline: $0.41 \pm 0.03$; P3: $0.32 \pm 0.04)$. All animals omitted slightly more trials during $\mathrm{P} 3$ than at baseline (main effect of time: $\mathrm{F}(1,40)=7.4 ; \quad p=0.01 ; \quad$ baseline: $4.00 \pm 6.03 \% ; \quad \mathrm{P} 3$ : $11.73 \pm 2.72 \%)$, but there was no main effect of group and no interaction between the two variables (both $p>0.22$ ). Thus, in essence, all animals regained baseline performance prior to the initiation of the treatment with haloperidol or clozapine and the test of AMPH challenges.

\section{Effects of Haloperidol and Clozapine}

To characterize the performance effects of the antipsychotic treatments, the performance of animals on all days, except the 3 days when AMPH challenges were given (days 1, 5, 10), was analyzed. To determine the potential effects of continued treatment with haloperidol or clozapine, the effects of the drug treatments on the performance of AMPH- and SAL-pretreated animals were analyzed over two blocks of treatment days (days 2, 3, $4 v s 6,7,8,9$ ) and compared with animals that were neither pre-treated with AMPH nor treated with haloperidol or clozapine.

Treatment with haloperidol alone did not significantly affect the performance of animals, irrespective of their pretreatment history. For all measures of performance, there were no main effects of group (SAL/VEH $v s \mathrm{SAL} / \mathrm{HAL}$ vs $\mathrm{AMPH} / \mathrm{HAL})$ or block, and no significant interactions between the effects of group, block and signal duration (where applicable; all $p>0.16$ ). Likewise, errors of omission were not significantly affected by the treatment with haloperidol (all $p>0.08$ ).

In contrast, clozapine treatment impaired the performance of animals pretreated with saline but not of animals that received AMPH during the pretreatment period. As Illustrated in Figure 4, clozapine reduced the animals' hit rate (omnibus ANOVA over SAL/VEH, SAL/CLOZ, AMPH/ CLOZ: $\mathrm{F}(2,18)=15.55 ; p<0.001)$ and increased the number of trials that were omitted $(\mathrm{F}(2,18)=3.65 ; p=0.009)$. The animals' ability to correctly reject nonsignal events was not significantly affected by clozapine $(\mathrm{F}(2,18)=1.30 ; p=0.28)$, and the effects on the collapsed measure VI likewise remained insignificant $(\mathrm{F}(2,18)=2.72 ; p=0.09)$. The effects of clozapine on hits and omissions did not differ between the two blocks of treatments and there were no interactions involving block (all $p>0.36$ ). Likewise, hits remained signal duration dependent as indicated by the absence of significant interactions involving signal duration (all $p>0.85$ ). Figure 4 illustrates that multiple comparisons indicated that for hits and omissions, the performance of clozapinetreated animals was impaired when compared with SAL/ VEH animals (both LSD $>0.33$, both $p<0.01$ ) and with AMPH/CLOZ animals (both LSD $>0.23$, both $p<0.03$ ). The performance of AMPH/CLOZ animals did not differ from that of SAL/VEH, further substantiating the protection of AMPH-pretreated animals from the detrimental performance effects of clozapine.

\section{Effects of AMPH Challenges as a Function of AMPH Pretreatment}

In animals pretreated with $\mathrm{AMPH}$, subsequent administration of $1.0 \mathrm{mg}$ per $\mathrm{kg}$ of $\mathrm{AMPH}$, a dose that did not affect their performance when given on day 1 of the pretreatment regimen (above), robustly impaired attentional performance. To document these effects, this analysis was limited to the comparison between the effects of AMPH challenges in AMPH/VEH and SAL/VEH groups (see Figure $1 \mathrm{~b}$ for groups). Following all three AMPH challenges (days 1, 5, and 10 of the antipsychotic treatment period; Figure 1a), the performance of animals pretreated with AMPH was significantly impaired when compared with animals that were not preexposed to AMPH (VI: $\mathrm{F}(1,12)=5.55 ; p=0.04$; Figure 5a). This main effect of AMPH challenge did not differ across the three individual challenges $(F(2,24)=$ $0.078 ; p=0.92)$. Separate analyses of the performance in signal and nonsignal trials indicated that the reductions in 

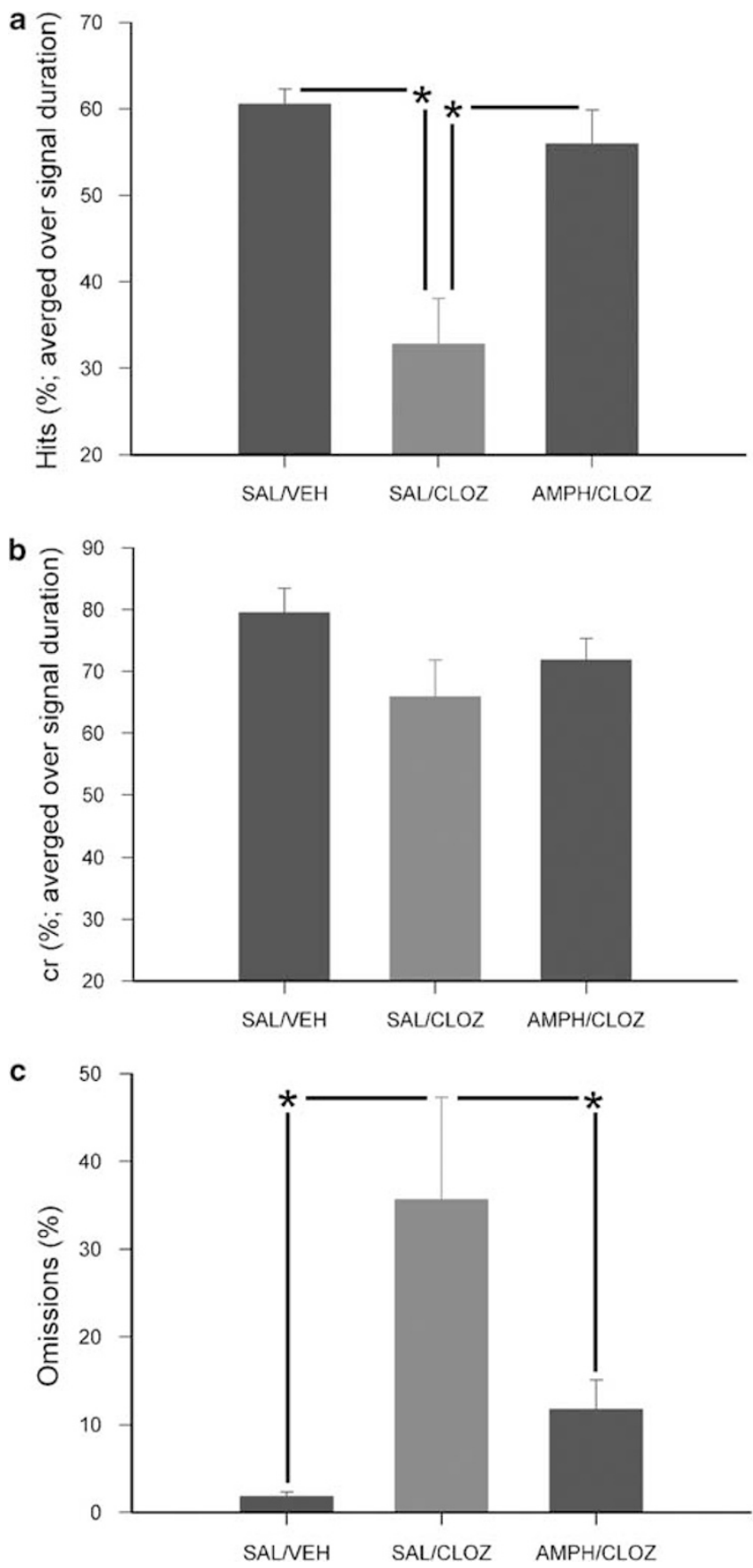

Figure 4 Performance of clozapine-treated animals (this analysis excluded the data from days I, 5, and 10 of the antipsychotic drug treatment regimen when the effects of amphetamine (AMPH) challenges were assessed). In animals pretreated with saline (SAL), clozapine treatment robustly impaired the performance in signal (a) but not nonsignal trials (b) when compared with animals pretreated with SAL and treated with the vehicle for clozapine $(V E H)$, and with animals pretreated with $\mathrm{AMPH}$ and treated with clozapine. Furthermore, clozapine treatment increased the errors of omission ( $c$; all data show M, SEM; * $p<0.05$ based on multiple comparisons; see 'Results' for analyses of variance (ANOVAs)). Treatment with haloperidol did not affect the animals' performance (not shown).

VI were primarily the result of decreases in hits following AMPH challenge in AMPH-pretreated animals (hits: $\mathrm{F}(1,12)=5.44 ; \quad p=0.04 ; \quad$ correct rejections:
$\mathrm{F}(1,12)=3.70 ; p=0.08$; see Figure $5 \mathrm{~b}$ and $\mathrm{c})$. Following AMPH challenges, all animals' hit rates remained signal duration dependent (main effect of duration: $F(2,26)=$ 62.17; $p<0.005$; group $\times$ duration: $\mathrm{F}(2,24)=1.05 ; p=0.36$; Figure 5). Finally, AMPH challenges did not differentially affect the number of omitted trials by AMPH and SAL-pretreated animals $(\mathrm{F}(1,12)=1.19 ; p=0.66 ; 4.85 \pm$ $1.77 \%$ omissions per session). There were no effects of AMPH challenges on the performance of subsequent sessions/days.

\section{Attenuation of the Detrimental Attentional Effects of AMPH Challenges by Haloperidol and Clozapine}

During the 10-day treatment period with haloperidol or clozapine, all animals received three AMPH challenges, on days 1,5 , and 10 into the antipsychotic treatment regimen. As described above, in AMPH-pretreated animals that were not treated with haloperidol or clozapine (AMPH/VEH), but not in SAL/VEH animals, these challenges robustly disrupted attentional performance. Furthermore, as already described above, clozapine treatment alone impaired the animals' performance. Therefore, and in order to avoid confounds resulting impaired performance in control animals, the effects of haloperidol and clozapine in interaction with AMPH challenges were analyzed on the basis of comparisons between AMPH-pretreated animals that received haloperidol, clozapine, or vehicle (AMPH/ HAL, AMPH/CLOZ, AMPH/VEH) and the performance of animals that were never treated with any drug (SAL/VEH) but received AMPH challenges. As already established, acutely administered AMPH (1.0 mg per $\mathrm{kg}$ ) did not affect the performance of drug-naïve animals, and this held true for the challenges in SAL/VEH animals (compared with their baseline performance prior to the AMPH-pretreatment regimen; all $p>0.12$ ). As an omnibus ANOVA comparing the performance effects of AMPH challenges in AMPH/ $\mathrm{VEH}, \mathrm{AMPH} / \mathrm{HAL}$, and AMPH/CLOZ animals indicated a significant group difference $(\mathrm{F}(2,18)=4.52 ; p=0.026)$, the results from the multiple comparisons are described separately below.

Effects of haloperidol. As pointed out below, the haloperidol-induced improvement of the performance of AMPHpretreated animals, when compared with the performance of $\mathrm{AMPH} / \mathrm{VEH}$ rats, just failed to reach statistical significance. On the other hand, the improvement was sufficient to render the performance of AMPH-pretreated animals to be statistically similar with the performance of SAL/VEH rats. In terms of VI, the performance of AMPH/ HAL did not differ significantly from AMPH/SAL animals $\mathrm{F}(1,12)=4.39 ; p=0.053)$, reflecting that AMPH challenges were equally effective in both groups (2- and 3-way interactions between group, signal duration and day: all $p>0.15$; Figure 6). Likewise, in the analyses of the individual measures of performance, significant effects of haloperidol were not found (all $p>0.08$ ). However, the trends for haloperidol-induced attenuation of the detrimental effects of AMPH challenges were sufficient to bring the performance of AMPH-pretreated animals up to the level of control animals (VI: $\mathrm{F}(1,12)=0.82 ; p=0.38$; hits, correct rejections: both $p>0.38)$. 

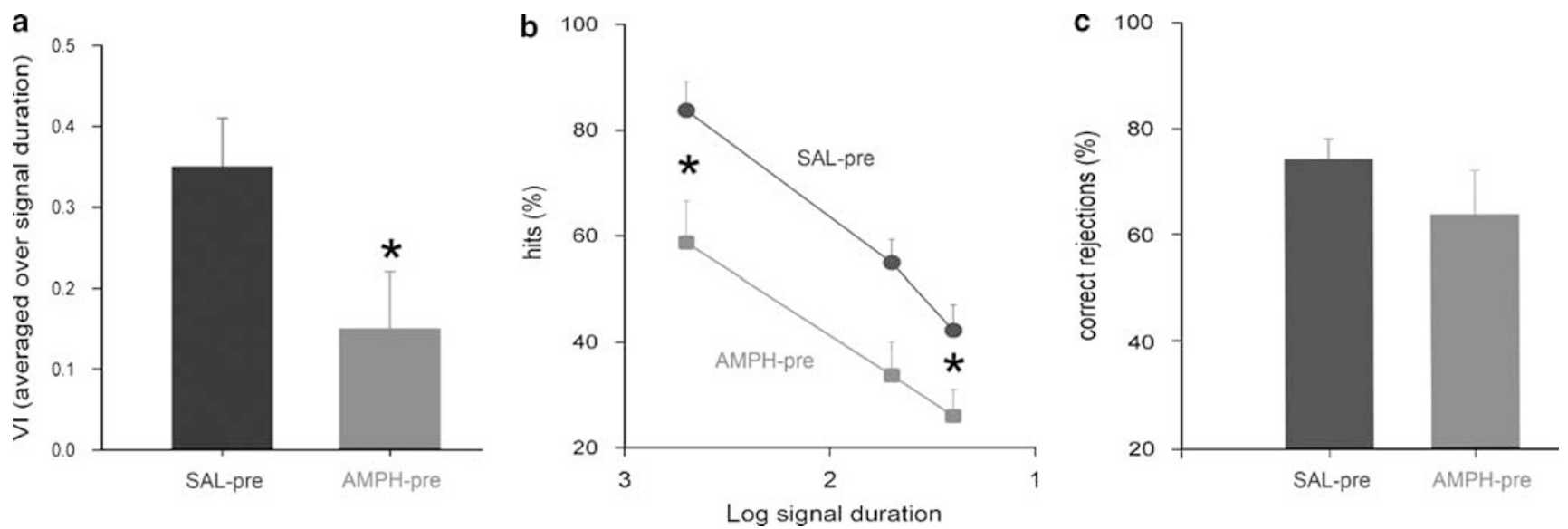

Figure 5 Effects of amphetamine (AMPH) challenges (I mg per kg) on vigilance index ( $\mathrm{VI}$ ) (a), hits (b) and correct rejections (c) of $\mathrm{AMPH}$ - or saline (SAL)-pretreated animals (M, SEM). As there were no significant differences between the effects of the three challenges (days 1 , 5, and I0 during the treatment with antipsychotic drugs), the graphs show data collapsed over all three tests. AMPH robustly impaired the overall performance as indicated by $\mathrm{VI}$, and this effect was due primarily to a decrease in hits ( $P<0.05$ based on multiple comparisons).

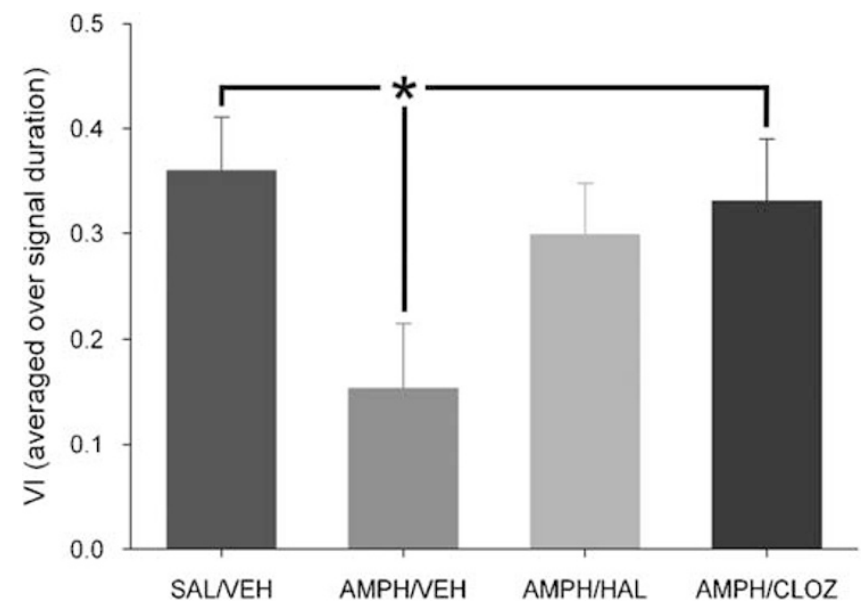

Figure 6 Attenuation of the detrimental performance effects of amphetamine $(\mathrm{AMPH})$ challenges by haloperidol and clozapine treatment (vigilance index (VI); M, SEM). Although the performance of AMPH/HAL (haloperidol)-treated animals did not significantly differ from AMPH/VEH (vehicle) animals, the treatment with haloperidol was sufficient to elevate the performance of $\mathrm{AMPH}$-pretreated and -challenged animals to the level of control animals (see 'Results') and also to AMPH/CLOZ (clozapine) animals. Clozapine was slightly, but not significantly more efficacious than haloperidol, as reflected by a significant difference between the performance of AMPH/NEH and AMPH/CLOZ animals (see 'Results' for significant omnibus analysis of variance (ANOVA); ${ }^{*} p<0.05$ based on multiple comparisons).

Effects of clozapine. Compared with the effects of haloperidol, clozapine more robustly attenuated the detrimental effects of AMPH challenges, yielding a significantly higher level of performance when compared with AMPH/ SAL animals (VI: F1, $12=4.79 ; p=0.049$; Figure 6). This effect did not interact with signal duration and did not differ across the three AMPH challenges (both $p>0.08$ ), indicating that chronic clozapine administration did not produce more efficacious effects than acute administration. The effects found in the analysis of VI reflected the combination of trends for increases in hits as well as correct rejections, neither of which gained significance when individually analyzed (all main effects and two-way interactions with signal duration and day: all $p>0.06$ ). The analysis of hits indicated a significant interaction between group, day and signal duration $(\mathrm{F}(4,48)=2.87 ; p=0.03)$; however, multiple comparisons failed to locate the basis for this interaction.

As was the case for the analysis of the effects of haloperidol, an important second component of the claim that the treatment with clozapine attenuated the effects of AMPH challenges is the demonstration that the performance of AMPH/CLOZ recovered to control levels, as indicated by the performance of SAL/VEH rats. This analysis indicated that, in terms of VI as well as the individual measures of performance, performance did not differ between these two groups and conditions (all $p>0.24$ ).

Finally, a direct comparison of the effects of AMPH challenges on the performance of AMPH/HAL and AMPH/ CLOZ rats did not reveal any differences in the efficacy of clozapine and haloperidol in attenuating the detrimental performance effects of AMPH challenges (all $p>0.78$ ).

Comparisons with baseline performance. Post hoc analyses were conducted to determine the degree to which the treatment with haloperidol and clozapine restored the performance of AMPH-pretreated and -challenged animals to the level of drug-naïve animals (AMPH/HAL or AMPH/ $\mathrm{CLOZ}$ against baseline performance recorded prior to the onset of the pretreatment regimen). The performance of AMPH/HAL animals remained below baseline levels (VI: $\mathrm{F}(3,18)=3.42 ; p=0.04)$. However, the performance of clozapine-treated animals did not differ from baseline (VI: $\mathrm{F}(3,18)=1.63 ; p=0.21$ ).

\section{DISCUSSION}

The main results form this experiment can be summarized as follows. Both haloperidol and clozapine attenuated the detrimental attentional effects of AMPH challenges in AMPH-pretreated animals. Overall, the beneficial effects of 
clozapine were statistically more robust, but not more efficacious, when compared directly to haloperidol. Clozapine, but not haloperidol, disrupted the performance of otherwise drug-naïve animals; such disruption was not seen in AMPH-pretreated animals.

Administration of clozapine, but not haloperidol, impaired the performance of SAL-pretreated animals. Most studies assessing the effects of low doses of clozapine on various behaviors did not observe effects of the drug per se, including on startle response and social interaction performance (Rueter et al, 2004). It needs to be noted that experiments assessing the putative beneficial or attenuating effects of clozapine frequently did not include a vehicle/ clozapine group, limiting comparisons with other studies (Abdul-Monim et al, 2006; Dunn and Killcross, 2006). However, the performance of tasks involving attentional processes has been previously reported to be impaired by similar doses of clozapine (Amitai et al, 2007; Cheal, 1984). The study by Amitai et al (2007) is of particular interest as they observed a decrease in the percent correct responses in rats performing the five-choice serial reaction time task following $3 \mathrm{mg}$ per $\mathrm{kg}$ clozapine, albeit a considerably smaller decrease than observed in the present experiment. Similar to the present results, Amitai et al (2007) did not observe effects of haloperidol on attentional performance.

There is sufficient evidence concerning the neurobiological mechanisms that mediate the detection of signals in such attention tasks to hypothesize that disruption of cortical cholinergic neurotransmission represents the primary mechanism responsible for decreases in response accuracy in signal trials (Apparsundaram et al, 2005; Dalley et al, 2004; McGaughy and Sarter, 1998; Parikh et al, 2007; Robbins, 2002; Sarter et al, 2005a). Thus, it is intriguing to speculate that the antimuscarinic properties of clozapine (for review see Kinon and Lieberman, 1996) mediated the effects on the performance of otherwise drug-naïve animals (see also Minzenberg et al, 2004). However, this speculation may be limited by questions about the antimuscarinic efficacy of clozapine when administered at such low dose (Chew et al, 2006).

AMPH-pretreated animals were not affected by clozapine treatment. Similar to our previous experiment (Kozak et al, 2007), the performance of animals pretreated with AMPH recovered completely during the 10-day period between AMPH pretreatment and the test of AMPH challenges. However, the results described in Kozak et al. (2007)suggest that the 'normal' attentional performance of AMPHpretreated rats was mediated via abnormally high increases in prefrontal ACh release, reaching 250-300\% increase over baseline when compared with $150 \%$ in task-performing, vehicle-treated animals (see Figure 4 in Kozak et al, 2007). These augmented levels of ACh release were interpreted as indicating that AMPH-pretreated animals required more cognitive effort (defined in Sarter et al, 2006) to maintain normal levels of attentional performance. It may be speculated that these augmented levels of cortical cholinergic neurotransmission counteracted the anticholinergic efficacy of clozapine and therefore 'protected' AMPHpretreated animals from the detrimental effects of this compound. Alternatively, as a result of the AMPH pretreatment, elevated levels of dopaminergic activity evoked by task performance may have provided sufficient D1 receptor stimulation to attenuate the detrimental effects of clozapine (Castner et al, 2000; Goldman-Rakic et al, 2004).

The absence of effects of haloperidol on attentional performance in drug-naïve animals indicates that with respect to low doses of D2 antagonists, defined as occupying $\sim 50 \%$ of dopamine D2 receptors (Kapur et al, 2003), the notion that FGAs such as haloperidol necessarily disrupt cognitive functions (Beuzen et al, 1999; Ehlis et al, 2007; Saeedi et al, 2006) may be a function of receptor occupancy, with $>50 \%$ D2 receptor occupancy expected to impair attentional performance in control subjects (Saeedi et al, 2006). The absence of detrimental effects of low doses of haloperidol in control subjects and the demonstration of beneficial cognitive effects in patients by equivalent, low doses of haloperidol (Green et al, 2002; Harvey et al, 2005; Keefe et al, 2006b; Mishara and Goldberg, 2004; Remillard et al, 2005; Rollnik et al, 2002) together suggest that conclusions about the cognitive profile of FGAs require careful consideration of dose and receptor occupancy.

Although there was a minor difference in the statistical analysis of the effects of haloperidol and clozapine against the effects of AMPH challenges, both compounds in essence attenuated the detrimental effects of these challenges. This finding contrasts with the prior results indicating that only clozapine, but not haloperidol, attenuates the behavioral effects of phencylcidine (Abdul-Monim et al, 2006; Dunn and Killcross, 2006). While phencylcidine/ketamine models have been productively employed to model other cognitive deficits associated with schizophrenia (Abdul-Monim et al, 2006; Dunn and Killcross, 2006; Jentsch and Roth, 1999), the present results correspond with the view that with respect to the modeling of specifically the attentional impairments of schizophrenia, phencylcidine/ketamine models may be less useful (Featherstone et al, 2007; Fletcher et al, 2005; Nelson et al, 2002). Given that the available clinical evidence does not suggest robust differences between the pro-cognitive efficacy of low doses of haloperidol and clozapine (see 'Introduction'), our results suggest that the present experimental paradigm is capable of reproducing these effects, thereby meeting an available criterion for predictive validity (Hagan and Jones, 2005).

In the present experiment, clozapine and haloperidol fully reversed the detrimental effects of AMPH challenges in AMPH-pretreated animals. While this result may be considered a limitation of the translational validity of our findings, it is plausible that this result reflects the relatively low demands on top-down control of attention assessed under standard, or baseline, task conditions. We have recently observed that the attentional performance of AMPH-pretreated animals is extraordinarily sensitive to distractors (Young et al, 2007), corresponding with the well-documented distractibility of schizophrenic patients (Gorissen et al, 2005; Grillon et al, 1990). It is likely that low-dose antipsychotic treatments are less efficacious in reversing the attentional impairments of AMPH-pretreated animals when tested under conditions requiring increases in cognitive effort (Sarter et al, 2006), thereby mirroring more closely the effect size observed in patients.

We can only speculate about the neurobiological mechanisms underlying the beneficial effects of haloperidol and clozapine in interaction with AMPH challenges. Compared with the pharmacological profile of haloperidol, the effects 
of clozapine are diverse and include affinity to a wide array of receptors including dopamine D4, noradrenergic $\alpha 2$, serotonergic 5-HT2, and cholinergic muscarinic M2 receptors (Kinon and Lieberman, 1996; Miyamoto et al, 2005; Nasrallah, 2007; Van Tol et al, 1992). As briefly mentioned in the 'Introduction', our evidence indicates that following AMPH challenges in AMPH-pretreated rats, the cortical cholinergic input system fails to respond to, and thereby to mediate, the performance of this task (Kozak et al, 2007). In this context, it is noteworthy that we also demonstrated that the consequences of AMPH pretreatment and -challenge on cholinergic activity did not manifest in control animals not performing the attention task. Therefore, the present results may not generalize to a test of the effects of the antipsychotic treatments in interaction with AMPH pretreatment and -challenges on other behavioral or cognitive operations that do not, or not to the same degree, depend on cortical cholinergic activity (see also Sarter et al, 2007). Furthermore, we hypothesized that the frozen cortical cholinergic input system in AMPH-pretreated and -challenged animals resulted from a disruption of limbictelencephalic circuitry (Goto and Grace, 2005; Homayoun and Moghaddam, 2006) involving, as a major final pathway, the projection from the nucleus accumbens to the cholinergic basal forebrain (Neigh et al, 2004; NeighMcCandless et al, 2002; Zmarowski et al, 2005, 2007). Haloperdol and clozapine may restore a critical mechanism in the cortical-mesolimbic-basal forebrain interplay, therefore restoring the ability to recruit the basal forebrain cholinergic system for the mediation of attentional performance (see also Barak and Weiner, 2007). We could speculate further that once recruited again, performanceassociated cholinergic activity supersedes normal levels of activity, therefore supporting normal performance under challenging conditions (similar to the discussion above) and effectively counteracting the antimuscarinic properties of clozapine. As the beneficial effects of clozapine were more robust when compared with haloperidol, as indicated by the results of the multiple comparisons, it is plausible that the ability of clozapine, but not haloperidol, to stimulate cortical ACh release (Ichikawa et al, 2002) contributes to the efficacy of clozapine to restore attentional performance. Moreover, if these speculations were relevant, this experimental paradigm would be expected to be highly sensitive for the detection of efficacy of polypharmacological treatment approaches thought to enhance cholinergic neurotransmission (Li et al, 2007b).

In the absence of information about the neuropharmacological mechanisms mediating the beneficial attentional effects of haloperidol and clozapine in AMPH-pretreated and AMPH challenged animals, we cannot completely exclude that this test detects primarily D2 receptor blockade and thus antipsychotic efficacy (Geyer, 2006; Kapur and Remington, 2001). If this was the case, the present test would be concluded to assess primarily the cognitive disruption that is associated with acute disease periods (Laruelle et al, 1999) and the secondary cognitive benefits of antipsychotic efficacy, as opposed to the residual and persistent cognitive deficits apparent during remission of this disorder (Brewer et al, 2006; Keefe et al, 2006a). However, the slightly more robust effects of clozapine are not consistent with this hypothesis. Moreover, given how little we know about the multiple psychopathophysiologial mechanisms that mediate the wide range of symptoms of schizophrenia, and about the interdependencies between symptoms traditionally categorized as positive, negative, and cognitive symptoms (Strauss, 1993), the construct validity of the present model remains difficult to determine. Therefore, in conclusion, the potential usefulness of the present results concerns primarily the detection of the moderately beneficial cognitive effects of low-dose antipsychotic drugs in an animal model. This model may be of use for the detection and characterization of new and more efficacious treatments targeting the cognitive deficits of schizophrenic patients.

\section{ACKNOWLEDGEMENTS}

These studies were supported by NIH grants RO1 MH063114 and KO2 NH01072 (MS). Vicente Martinez was supported by an Interdisciplinary Research Training Grant in Substance Abuse (T32 DA007267-12; University of Michigan Substance Abuse Research Center; UMSARC). We thank Elise Demeter for corrections to the final draft.

\section{DISCLOSURE/CONFLICT OF INTEREST}

The research described in this article has been supported by $\mathrm{NIH}$ grants RO1 MH063114 and KO2 NH01072 (MS). Vicente Martinez was supported by an Interdisciplinary Research Training Grant in Substance Abuse (T32 DA007267-12; University of Michigan Substance Abuse Research Center; UMSARC).

Listing for each author, detailing the names of organizations, institutions, companies, and individuals, including intermediaries such as subcontractors or conference organizers, from whom they have received compensation for professional services in any of the previous 3 years, or from whom they anticipate receiving such compensation in the near future, whether or not these affiliations appear to have any relevance to the topic covered in the submission.

Vicente Martinez: None to report.

Martin Sarter: Dr Sarter has received honoraria for speaking at Abbott Laboratories and Pfizer Pharmaceuticals and has received research support from Abbott Laboratories and Pfizer Pharmaceuticals. Dr Sarter received an honorarium for a talk at The Mitre Corporation (McLean, VA) and for a talk at an event sponsored by CanCog Technologies Inc. (Toronto). Dr Sarter is a consultant for Sonexa Therapeutics Inc.

\section{REFERENCES}

Abdul-Monim Z, Reynolds GP, Neill JC (2006). The effect of atypical and classical antipsychotics on sub-chronic PCP-induced cognitive deficits in a reversal-learning paradigm. Behav Brain Res 169: 263-273.

Amitai N, Semenova S, Markou A (2007). Cognitive-disruptive effects of the psychotomimetic phencyclidine and attenuation by atypical antipsychotic medications in rats. Psychopharmacology 193: 521-537.

Angrist B (1994). Amphetamine psychosis: clinical variations of the syndrome. In: Cho AK, Segal DS (eds). Amphetamine and Its Analogues. Academic Press: San Diego. pp 387-414. 
Apparsundaram S, Martinez V, Parikh V, Kozak R, Sarter M (2005). Increased capacity and density of choline transporters situated in synaptic membranes of the right medial prefrontal cortex of attentional task-performing rats. J Neurosci 25: 3851-3856.

Arnold HM, Burk JA, Hodgson EM, Sarter M, Bruno JP (2002). Differential cortical acetylcholine release in rats performing a sustained attention task versus behavioral control tasks that do not explicitly tax attention. Neuroscience 114: 451-460.

Barak S, Weiner I (2007). Scopolamine induces disruption of latent inhibition which is prevented by antipsychotic drugs and an acetylcholinesterase inhibitor. Neuropsychopharmacology 32: 989-999.

Beuzen JN, Taylor N, Wesnes K, Wood A (1999). A comparison of the effects of olanzapine, haloperidol and placebo on cognitive and psychomotor functions in healthy elderly volunteers. J Psychopharmacol 13: 152-158.

Braff DL, Light GA (2004). Preattentional and attentional cognitive deficits as targets for treating schizophrenia. Psychopharmacology (Berl) 174: 75-85.

Brewer WJ, Wood SJ, Phillips LJ, Francey SM, Pantelis C, Yung AR et al. (2006). Generalized and specific cognitive performance in clinical high-risk cohorts: a review highlighting potential vulnerability markers for psychosis. Schizophr Bull 32: 538-555.

Castner SA, Goldman-Rakic PS (1999). Long-lasting psychotomimetic consequences of repeated low-dose amphetamine exposure in rhesus monkeys. Neuropsychopharmacology 20: 10-28.

Castner SA, Goldman-Rakic PS (2003). Amphetamine sensitization of hallucinatory-like behaviors is dependent on prefrontal cortex in nonhuman primates. Biol Psychiatry 54: 105-110.

Castner SA, Goldman-Rakic PS, Williams GV (2004). Animal models of working memory: insights for targeting cognitive dysfunction in schizophrenia. Psychopharmacology (Berl) 174: 111-125.

Castner SA, Vosler PS, Goldman-Rakic PS (2005). Amphetamine sensitization impairs cognition and reduces dopamine turnover in primate prefrontal cortex. Biol Psychiatry 57: 743-751.

Castner SA, Williams GV, Goldman-Rakic PS (2000). Reversal of antipsychotic-induced working memory deficits by short-term dopamine D1 receptor stimulation. Science 287: 2020-2022.

Cheal M (1984). Differential effects of haloperidol and clozapine on attention. Psychopharmacology (Berl) 84: 268-273.

Cheng YF, Paalzow LK (1992). Linear pharmacokinetics of haloperidol in the rat. Biopharm Drug Dispos 13: 69-76.

Chew ML, Mulsant BH, Pollock BG, Lehman ME, Greenspan A, Kirshner MA et al. (2006). A model of anticholinergic activity of atypical antipsychotic medications. Schizophr Res 88: 63-72.

Crider A, Solomon PR, McMahon MA (1982). Disruption of selective attention in the rat following chronic d-amphetamine administration: relationship to schizophrenic attention disorder. Biol Psychiatry 17: 351-361.

Dalley JW, Theobald DE, Berry D, Milstein JA, Laane K, Everitt BJ et al. (2005). Cognitive sequelae of intravenous amphetamine self-administration in rats: evidence for selective effects on attentional performance. Neuropsychopharmacology 30: 525-537.

Dalley JW, Theobald DE, Bouger P, Chudasama Y, Cardinal RN, Robbins TW (2004). Cortical cholinergic function and deficits in visual attentional performance in rats following 192 IgGsaporin-induced lesions of the medial prefrontal cortex. Cereb Cortex 14: 922-932.

Dunn MJ, Killcross S (2006). Clozapine but not haloperidol treatment reverses sub-chronic phencyclidine-induced disruption of conditional discrimination performance. Behav Brain Res 175: 271-277.

Ehlis AC, Herrmann MJ, Pauli P, Stoeber G, Pfuhlmann B, Fallgatter AJ (2007). Improvement of prefrontal brain function in endogenous psychoses under atypical antipsychotic treatment. Neuropsychopharmacology 32: 1669-1677.
Featherstone RE, Kapur S, Fletcher PJ (2007). The amphetamineinduced sensitized state as a model of schizophrenia. Prog Neuropsychopharmacol Biol Psychiatry 31: 1556-1571.

Fletcher PJ, Tenn CC, Rizos Z, Lovic V, Kapur S (2005). Sensitization to amphetamine, but not PCP, impairs attentional set shifting: reversal by a D1 receptor agonist injected into the medial prefrontal cortex. Psychopharmacology (Berl) 183: 190-200.

Fletcher PJ, Tenn CC, Sinyard J, Rizos Z, Kapur S (2007). A sensitizing regimen of amphetamine impairs visual attention in the 5-choice serial reaction time test: reversal by a D1 receptor agonist injected into the medial prefrontal cortex. Neuropsychopharmacology 32: 1122-1132.

Floresco SB, Geyer MA, Gold LH, Grace AA (2005). Developing predictive animal models and establishing a preclinical trials network for assessing treatment effects on cognition in schizophrenia. Schizophr Bull 31: 888-894.

Frey PW, Colliver JA (1973). Sensitivity and responsivity measures for discrimination learning. Learning and Motivation 4: 327-342.

Geyer MA (2006). Are cross-species measures of sensorimotor gating useful for the discovery of procognitive cotreatments for schizophrenia? Dialogues Clin Neurosci 8: 9-16.

Goldman-Rakic PS, Castner SA, Svensson TH, Siever LJ, Williams GV (2004). Targeting the dopamine D1 receptor in schizophrenia: insights for cognitive dysfunction. Psychopharmacology (Berl) 174: 3-16.

Gorissen M, Sanz JC, Schmand B (2005). Effort and cognition in schizophrenia patients. Schizophr Res 78: 199-208.

Goto Y, Grace AA (2005). Dopamine-dependent interactions between limbic and prefrontal cortical plasticity in the nucleus accumbens: disruption by cocaine sensitization. Neuron 47: 255-266.

Green MF, Marder SR, Glynn SM, McGurk SR, Wirshing WC, Wirshing DA et al. (2002). The neurocognitive effects of lowdose haloperidol: a two-year comparison with risperidone. Biol Psychiatry 51: 972-978.

Greenwald A, Gonzalez R, Harris R, Guthrie D (1996). Effects sizes and $p$-values: what should be reported and what should be replicated. Psychophysiology 33: 157-183.

Grillon C, Courchesne E, Ameli R, Geyer MA, Braff DL (1990). Increased distractibility in schizophrenic patients. Electrophysiologic and behavioral evidence. Arch Gen Psychiatry 47: 171-179.

Hagan JJ, Jones DN (2005). Predicting drug efficacy for cognitive deficits in schizophrenia. Schizophr Bull 31: 830-853.

Hajos M (2006). Targeting information-processing deficit in schizophrenia: a novel approach to psychotherapeutic drug discovery. Trends Pharmacol Sci 27: 391-398.

Harvey PD, Rabinowitz J, Eerdekens M, Davidson M (2005). Treatment of cognitive impairment in early psychosis: a comparison of risperidone and haloperidol in a large long-term trial. Am J Psychiatry 162: 1888-1895.

Homayoun H, Moghaddam B (2006). Progression of cellular adaptations in medial prefrontal and orbitofrontal cortex in response to repeated amphetamine. J Neurosci 26: 8025-8039.

Ichikawa J, Dai J, O'Laughlin IA, Fowler WL, Meltzer HY (2002). Atypical, but not typical, antipsychotic drugs increase cortical acetylcholine release without an effect in the nucleus accumbens or striatum. Neuropsychopharmacology 26: 325-339.

Jentsch JD, Roth RH (1999). The neuropsychopharmacology of phencyclidine: from NMDA receptor hypofunction to the dopamine hypothesis of schizophrenia. Neuropsychopharmacology 20: 201-225.

Kapur S (2003). Psychosis as a state of aberrant salience: a framework linking biology, phenomenology, and pharmacology in schizophrenia. Am J Psychiatry 160: 13-23.

Kapur S, Remington G (2001). Dopamine D(2) receptors and their role in atypical antipsychotic action: still necessary and may even be sufficient. Biol Psychiatry 50: 873-883. 
Kapur S, VanderSpek SC, Brownlee BA, Nobrega JN (2003). Antipsychotic dosing in preclinical models is often unrepresentative of the clinical condition: a suggested solution based on in vivo occupancy. J Pharmacol Exp Ther 305: 625-631.

Keefe RS, Bilder RM, Harvey PD, Davis SM, Palmer BW, Gold JM et al. (2006a). Baseline neurocognitive deficits in the CATIE schizophrenia trial. Neuropsychopharmacology 31: 2033-2046.

Keefe RS, Seidman LJ, Christensen BK, Hamer RM, Sharma T, Sitskoorn MM et al. (2006b). Long-term neurocognitive effects of olanzapine or low-dose haloperidol in first-episode psychosis. Biol Psychiatry 59: 97-105.

Kinon BJ, Lieberman JA (1996). Mechanisms of action of atypical antipsychotic drugs: a critical analysis. Psychopharmacology (Berl) 124: 2-34.

Kozak R, Bruno JP, Sarter M (2006). Augmented prefrontal acetylcholine release during challenged attentional performance. Cereb Cortex 16: 9-17.

Kozak R, Martinez V, Young D, Brown H, Bruno JP, Sarter M (2007). Toward a neuro-cognitive animal model of the cognitive symptoms of schizophrenia: disruption of cortical cholinergic neurotransmission following repeated amphetamine exposure in attentional task-performing, but not non-performing, rats. Neuropsychopharmacology 32: 2074-2086.

Laruelle M (2000). The role of endogenous sensitization in the pathophysiology of schizophrenia: implications from recent brain imaging studies. Brain Res Brain Res Rev 31: 371-384.

Laruelle M, Abi-Dargham A (1999). Dopamine as the wind of the psychotic fire: new evidence from brain imaging studies. J Psychopharmacol 13: 358-371.

Laruelle M, Abi-Dargham A, Gil R, Kegeles L, Innis R (1999). Increased dopamine transmission in schizophrenia: relationship to illness phases. Biol Psychiatry 46: 56-72.

Li M, Fletcher PJ, Kapur S (2007a). Time course of the antipsychotic effect and the underlying behavioral mechanisms. Neuropsychopharmacology 32: 263-272.

Li Z, Bonhaus DW, Huang M, Prus AJ, Dai J, Meltzer HY (2007b). AC260584 (4-[3-(4-butylpiperidin-1-yl)-propyl]-7-fluoro-4Hbenzo[1,4]oxazin-3-one), a selective muscarinic M1 receptor agonist, increases acetylcholine and dopamine release in rat medial prefrontal cortex and hippocampus. Eur J Pharmacol 572: 129-137.

Lieberman JA, Sheitman BB, Kinon BJ (1997). Neurochemical sensitization in the pathophysiology of schizophrenia: deficits and dysfunction in neuronal regulation and plasticity. Neuropsychopharmacology 17: 205-229.

Martinez V, Parikh V, Sarter M (2005). Sensitized attentional performance and Fos-immunoreactive cholinergic neurons in the basal forebrain of amphetamine-pretreated rats. Biol Psychiatry 57: 1138-1146.

Martinez V, Sarter M (2004). Lateralized attentional functions of cortical cholinergic inputs. Behav Neurosci 118: 984-991.

McGaughy J, Everitt BJ, Robbins TW, Sarter M (2000). The role of cortical cholinergic afferent projections in cognition: impact of new selective immunotoxins. Behav Brain Res 115: 251-263.

McGaughy J, Kaiser T, Sarter M (1996). Behavioral vigilance following infusions of 192 IgG-saporin into the basal forebrain: selectivity of the behavioral impairment and relation to cortical AChE-positive fiber density. Behav Neurosci 110: 247-265.

McGaughy J, Sarter M (1995). Behavioral vigilance in rats: task validation and effects of age, amphetamine, and benzodiazepine receptor ligands. Psychopharmacology (Berl) 117: 340-357.

McGaughy J, Sarter M (1998). Sustained attention performance in rats with intracortical infusions of 192 IgG-saporin-induced cortical cholinergic deafferentation: effects of physostigmine and FG 7142. Behav Neurosci 112: 1519-1525.

Minzenberg MJ, Poole JH, Benton C, Vinogradov S (2004). Association of anticholinergic load with impairment of complex attention and memory in schizophrenia. Am J Psychiatry 161: 116-124.
Mishara AL, Goldberg TE (2004). A meta-analysis and critical review of the effects of conventional neuroleptic treatment on cognition in schizophrenia: opening a closed book. Biol Psychiatry 55: 1013-1022.

Miyamoto S, Duncan GE, Marx CE, Lieberman JA (2005). Treatments for schizophrenia: a critical review of pharmacology and mechanisms of action of antipsychotic drugs. Mol Psychiatry 10: $79-104$

Moghaddam B (2002). Stress activation of glutamate neurotransmission in the prefrontal cortex: implications for dopamine-associated psychiatric disorders. Biol Psychiatry 51: 775-787.

Nasrallah HA (2007). Atypical antipsychotic-induced metabolic side effects: insights from receptor-binding profiles. $\mathrm{Mol}$ Psychiatry e-pub ahead of print.

Neigh GN, Arnold HM, Rabenstein RL, Sarter M, Bruno JP (2004). Neuronal activity in the nucleus accumbens is necessary for performance-related increases in cortical acetylcholine release. Neuroscience 123: 635-645.

Neigh-McCandless G, Kravitz BA, Sarter M, Bruno JP (2002). Stimulation of cortical acetylcholine release following blockade of ionotropic glutamate receptors in nucleus accumbens. Eur J Neurosci 16: 1259-1266.

Nelson CL, Burk JA, Bruno JP, Sarter M (2002). Effects of acute and repeated systemic administration of ketamine on prefrontal acetylcholine release and sustained attention performance in rats. Psychopharmacology 161: 168-179.

Parikh V, Kozak R, Martinez V, Sarter M (2007). Prefrontal acetylcholine release controls cue detection on multiple timescales. Neuron 56: 141-154.

Paulson PE, Camp DM, Robinson TE (1991). Time course of transient behavioral depression and persistent behavioral sensitization in relation to regional brain monoamine concentrations during amphetamine withdrawal in rats. Psychopharmacology (Berl) 103: 480-492.

Raedler TJ, Bymaster FP, Tandon R, Copolov D, Dean B (2007). Towards a muscarinic hypothesis of schizophrenia. Mol Psychiatry 12: 232-246.

Raedler TJ, Knable MB, Jones DW, Urbina RA, Gorey JG, Lee KS et al. (2003). In vivo determination of muscarinic acetylcholine receptor availability in schizophrenia. Am J Psychiatry 160: 118-127.

Remillard S, Pourcher E, Cohen H (2005). The effect of neuroleptic treatments on executive function and symptomatology in schizophrenia: a 1-year follow up study. Schizophr Res 80: 99-106.

Robbins TW (2002). The 5-choice serial reaction time task: behavioural pharmacology and functional neurochemistry. Psychopharmacology (Berl) 163: 362-380.

Robbins TW (2005). Synthesizing schizophrenia: a bottom-up, symptomatic approach. Schizophr Bull 31: 854-864.

Robinson TE, Becker JB (1986). Enduring changes in brain and behavior produced by chronic amphetamine administration: a review and evaluation of animal models of amphetamine psychosis. Brain Res 396: 157-198.

Robinson TE, Camp DM (1987). Long-lasting effects of escalating doses of d-amphetamine on brain monoamines, amphetamineinduced stereotyped behavior and spontaneous nocturnal locomotion. Pharmacol Biochem Behav 26: 821-827.

Robinson TE, Jurson PA, Bennett JA, Bentgen KM (1988). Persistent sensitization of dopamine neurotransmission in ventral striatum (nucleus accumbens) produced by prior experience with (+)-amphetamine: a microdialysis study in freely moving rats. Brain Res 462: 211-222.

Rollnik JD, Borsutzky M, Huber TJ, Mogk H, Seifert J, Emrich HM et al. (2002). Short-term cognitive improvement in schizophrenics treated with typical and atypical neuroleptics. Neuropsychobiology 45: 74-80. 
Rueter LE, Ballard ME, Gallagher KB, Basso AM, Curzon P, Kohlhaas KL (2004). Chronic low dose risperidone and clozapine alleviate positive but not negative symptoms in the rat neonatal ventral hippocampal lesion model of schizophrenia. Psychopharmacology (Berl) 176: 312-319.

Russig H, Murphy CA, Feldon J (2002). Clozapine and haloperidol reinstate latent inhibition following its disruption during amphetamine withdrawal. Neuropsychopharmacology 26: 765-777.

Saeedi H, Remington G, Christensen BK (2006). Impact of haloperidol, a dopamine D2 antagonist, on cognition and mood. Schizophr Res 85: 222-231.

Sarter M (2006). Preclinical research into cognition enhancers. Trends Pharmacol Sci 27: 602-608.

Sarter M, Bruno JP, Parikh V (2007). Abnormal neurotransmitter release underlying behavioral and cognitive disorders: toward concepts of dynamic and function-specific dysregulation. Neuropsychopharmacology 32: 1452-1461.

Sarter M, Gehring WJ, Kozak R (2006). More attention must be paid: the neurobiology of attentional effort. Brain Res Rev 51: $155-160$.

Sarter M, Hagan J, Dudchenko P (1992a). Behavioral screening for cognition enhancers: from indiscriminate to valid testing: part I. Psychopharmacology (Berl) 107: 144-159.

Sarter M, Hagan J, Dudchenko P (1992b). Behavioral screening for cognition enhancers: from indiscriminate to valid testing: part II. Psychopharmacology (Berl) 107: 461-473.

Sarter M, Hasselmo ME, Bruno JP, Givens B (2005a). Unraveling the attentional functions of cortical cholinergic inputs: interactions between signal-driven and top-down cholinergic modulation of signal detection. Brain Res Rev 48: 98-111.
Sarter M, Nelson CL, Bruno JP (2005b). Cortical cholinergic transmission and cortical information processing following psychostimulant-sensitization: implications for models of schizophrenia. Schizophr Bull 31: 117-138.

Strauss ME (1993). Relations of symptoms to cognitive deficits in schizophrenia. Schizophr Bull 19: 215-231.

Tenn CC, Fletcher PJ, Kapur S (2003). Amphetamine-sensitized animals show a sensorimotor gating and neurochemical abnormality similar to that of schizophrenia. Schizophr Res 64: 103-114.

Tenn CC, Fletcher PJ, Kapur S (2005). A putative animal model of the 'prodromal' state of schizophrenia. Biol Psychiatry 57: 586-593.

Van Tol HH, Wu CM, Guan HC, Ohara K, Bunzow JR, Civelli O et al. (1992). Multiple dopamine D4 receptor variants in the human population. Nature 358: 149-152.

Young D, Howe W, Martinez V, Bruno JP, Sarter M (2007). Neuronal mechanisms underlying the cognitive symptoms in a model of schizophrenia: prefrontal cholinergic inputs are necessary for attentional. Society for Neuroscience Annual Meeting (poster no. 606. 9). San Diego, CA.

Yui K, Goto K, Ikemoto S, Ishiguro T, Angrist B, Duncan GE et al. (1999). Neurobiological basis of relapse prediction in stimulantinduced psychosis and schizophrenia: the role of sensitization. Mol Psychiatry 4: 512-523.

Zar JH (1974). Biostatistical Analysis. Prentice Hall: Prentice Hall. Zmarowski A, Sarter M, Bruno JP (2005). NMDA and dopamine interactions in the nucleus accumbens modulate cortical acetylcholine release. Eur J Neurosci 22: 1731-1740.

Zmarowski A, Sarter M, Bruno JP (2007). Glutamate receptors in nucleus accumbens mediate regionally selective increases in cortical acetylcholine release. Synapse 61: 115-123. 